\title{
Prenatal dexamethasone 'programmes' hypotension, but stress-induced hypertension in adult offspring
}

\author{
David O'Regan, Christopher J Kenyon, Jonathan R Seckl and Megan C Holmes \\ Endocrinology Unit, Queen's Medical Research Institute, Centre for Cardiovascular Science, 47 Little France Crescent, Edinburgh EH16 4TJ, UK \\ (Correspondence should be addressed to M C Holmes; Email: megan.holmes@ed.ac.uk)
}

\begin{abstract}
Low birth weight in humans is predictive of hypertension in adult life. Although the mechanisms underlying this link remain unknown, fetal overexposure to glucocorticoids has been implicated. We previously showed that prenatal dexamethasone (DEX) exposure in the rat lowers birth weight and programmes adult hypertension. The current study aimed to further investigate the nature of this hypertension and to elucidate its origins. Unlike previous studies, we assessed offspring blood pressure (BP) with radiotelemetry, which is unaffected by stress artefacts of measurement. We show that prenatal DEX during the last week of pregnancy results in offspring of low birth weight (14\% reduction) that have lower basal BP in adulthood ( 4-8 $\mathrm{mmHg}$ lower); with the commonly expected hypertensive phenotype only being noted when these offspring are
\end{abstract}

subjected to even mild disturbance or a more severe stressor (up to $30 \mathrm{mmHg}$ higher than controls). Moreover, DEX-treated offspring sustain their stress-induced hypertension for longer. Promotion of systemic catecholamine release (amphetamine) induced a significantly greater rise of $\mathrm{BP}$ in the DEX animals ( $77 \%$ increase) over that observed in the vehicle controls. Additionally, we demonstrate that the isolated mesenteric vasculature of DEX-treated offspring display greater sensitivity to noradrenaline and other vasoconstrictors. We therefore conclude that altered sympathetic responses mediate the stressinduced hypertension associated with prenatal DEX programming.

Journal of Endocrinology (2008) 196, 343-352

\section{Introduction}

Much evidence suggests that transient adversity in the prenatal environment exerts permanent effects on subsequent physiology and increases disease risk in adult life (Curhan et al. 1996b, Fall et al. 1998, Law et al. 2001, Seckl 2004). A plethora of epidemiological studies have shown that low birth weight, a proposed surrogate for intrauterine adversity, is associated with hypertension (Barker 1990), type 2 diabetes (McCance et al. 1994), the metabolic syndrome and deaths from ischemic heart disease in later life (Curhan et al. 1996a, Barker 1999). To explain these links, the concept of developmental 'programming' has been advanced, whereby a factor acting during a critical developmental window affects the ontogeny of specifically vulnerable cell targets, permanently altering tissue structure and/or function and hence the eventual risk of disease (Benediktsson et al. 1993, Barker 2003, Seckl 2004). However, such environmentally determined developmental effects are widespread in the animal kingdom and often associate with phenotypes which appear to represent a finely balanced transient advantage in a particular environment. Such developmental 'trade-offs' can become disadvantageous late in the lifespan.

Fetal 'programming' may be investigated in a controlled manner using laboratory animals that age relatively rapidly and have similar or identical genetic backgrounds. In rats and many other mammalian species, fetal exposure to excess glucocorticoids via maternal stress, inhibition of placental $11 \beta$-hydroxysteroid dehydrogenase type 2 , the normal 'barrier' to maternal glucocorticoids, or its bypass with non-substrate synthetic glucocorticoids, such as dexamethasone (DEX), commonly used in obstetric practice, all lower birth weight. The adult offspring show permanently elevated glucose and insulin levels and hypertension (Levitt et al. 1996, Nyirenda et al. 1998, 2001, Langdown et al. 2001, Sugden et al. 2001). Although programmed increases in the expression of key hepatic gluconeogenic enzymes may later underpin hyperglycaemia (Nyirenda et al. 1998, 2001), little is known of the mechanisms by which glucocorticoids 'programme' higher blood pressure (BP) or whether this phenotype carries any advantage.

Prenatal DEX, specifically in the last trimester, affects the development and maturation of specific organs related to BP control and maintenance; notably the developing heart, kidney, vasculature and brain (Torres et al. 1997, Ortiz et al. 2003, Kreider et al. 2005, Roghair et al. 2005). Alterations in the activity or responsivity of the sympathetic nervous system (SNS), either systemically or in one of these specific regions, could provide a potential explanation for the manner in which prenatal glucocorticoids promote adulthood hypertension. Indeed, in humans, increased SNS activity has long been proposed as a mechanism to explain the pathogenesis of 
glucocorticoid-induced hypertension (Whitworth et al. 1995, Saruta 1996). Consistent with this hypothesis, elevated SNS activity, established in utero, links small size at birth with raised BP in adult life (Phillips \& Barker 1997). In rats, prenatal DEX alters the development of cardiac and central sympathetic innervation and activity (Slotkin et al. 1992, Bian et al. 1993). Permanent changes in the pattern and expression of adrenergic receptors (Huff et al. 1991, Bian et al. 1992) have the potential to alter vascular responsivity to vasoconstrictors. Similar findings have been reported with DEX administration during pregnancy in sheep (Stein et al. 1994, Padbury et al. 1995, Tseng et al. 1995).

To study more closely diurnal variation and the role of the SNS in adult BP in animals prenatally treated with excess glucocorticoids, we used the DEX-exposed rat model. Radiotelemetry (Anderson et al. 1999) enabled the remote recording of $\mathrm{BP}$ in conscious, unrestrained rats with minimal stress effects.

\section{Materials and Methods}

\section{Animals}

Adult Wistar rats (200-250 g; Harlan UK Ltd, Bichester, UK) were maintained under conditions of controlled lighting (lights on $0700-1900 \mathrm{~h}$ ) and temperature $\left(22^{\circ} \mathrm{C}\right)$ with ad libitum access to food (standard rat chow) and water. All experiments were performed according to the UK Animals (Scientific Procedures) Act, 1986.

\section{Prenatal treatments}

Virgin female rats were housed with male rats. Pregnancy was confirmed by the presence of a vaginal plug, checked every morning. Pregnant females were housed singly, and randomly assigned to one of two treatment groups ( $n=9-10$ per group). DEX $(100 \mu \mathrm{g} / \mathrm{kg}$ per day, dissolved in $4 \%$ ethanol in $0.9 \%$ saline, $200 \mu \mathrm{g} / \mathrm{ml}$; Sigma-Aldrich) was injected (subcutaneously) daily (0900 h) on embryonic days 15-21 inclusive (Nyirenda et al. 1998); control animals received vehicle (VEH) injections.

\section{Litters}

On the day of birth (postnatal day 1), litters were weighed, sexed and culled to eight pups per litter, retaining equal numbers of male and female pups where possible. Litters were then left undisturbed till weaning (postnatal day 21), apart from routine weekly maintenance. After weaning, male and female pups from each litter were housed in single sex groups of two to four. All rats underwent a minimum of 2 weeks of daily handling prior to being utilised in experiments. Females were tested during oestrus, confirmed by vaginal cytology. Epithelial cells were aspirated from the vagina with $1 \mathrm{ml}$ saline and placed on a glass slide for microscopic inspection. The oestrous cycle was then staged according to the Journal of Animal Technicians Association, 12, No. 1. Staging was independently verified by at least one other researcher/animal technician.
Radiotelemetry monitoring of offspring $B P$, heart rate and activity

BP (systolic BP, SBP; diastolic BP, DBP; mean arterial pressure, MAP and pulse pressure, PP), heart rate (HR), and activity were assessed by radiotelemetry (Dataquest IV, Data Sciences International, St Paul, MN, USA; Anderson et al. 1999). Randomly selected littermates (five males and five females, from eight vehicle and eight DEX litters) at 7-8 months were anaesthetised with halothane. A flexible catheter was secured in the abdominal aorta, and the telemetry transmitter was sutured to the abdominal wall. On recovery, rats were housed in individual cages, and each cage was placed over a receiver panel with output to a PC. Each cage and its receiver panel were housed in a specially designed steel cage rack, to prevent radio signal disturbance from neighbouring animals, and the rack was stored in a quiet room. After a 10-day recovery period, haemodynamic measurements were recorded for $10 \mathrm{~s}$ every $30 \mathrm{~min}$ (Khan et al. 2003).

\section{Induction of stress by disturbance, weighing and restraint procedure}

Offspring were subjected to a series of graded stressors: i) simple disturbance (a researcher entering their room); ii) being weighed and iii) restraint in a Perspex cylinder for $15 \mathrm{~min}$. To evaluate the stress response to weighing, haemodynamic measurements were recorded prior to and immediately after removal of the rat from its cage and again at 5-min post-weighing, when the animal was replaced. For the restraint procedure, measurements were collected prior to the rat being placed in the cylinder, throughout the 15-min restraint period, and at 15-min postrestraint, on being returned to its cage. A rest period of 2 days was allowed between experiments.

\section{Haemodynamic responses to alterations in catecholaminergic mechanisms}

Haemodynamic responses were collected for $15 \mathrm{~min}$ following a low dose of i.p. D-amphetamine $(0.5 \mathrm{mg} / \mathrm{kg})$, to cause systemic catecholamine release.

\section{Vascular responses to noradrenaline, vasopressin and potassium} chloride

Pairs of rats (one VEH and one DEX) were anaesthetised with sodium pentobarbitone, and the mesenteric vasculature was catheterised and perfused with Krebs bicarbonate Ringer's solution, and isolated as previously described (McGregor 1965). Perfusion pressure with constant flow rate was measured continuously via an Elcomatic EM 720 transducer, and recorded on a MacLab Chart V3.3.5 program (ADI, Oxford, UK). On alternate days, mesenteric preparations from each treatment group were attached to alternate transducers, to exclude the possibility of any positional artefact. Following a 15-min equilibration period, a brief 'wake-up' bolus of $20 \mu \mathrm{M}$ noradrenaline (NA; SigmaAldrich) was administered (Hadoke et al. 2006). 
Twelve pairs of mesenteric vasculature preparations from both male and female offspring were tested simultaneously for periods of 3 min with increasing concentrations of agonists in the following order: NA $(0 \cdot 1-20 \mu \mathrm{M})$, vasopressin (AVP; 0.5-20 nM; Sigma-Aldrich) and potassium chloride (KCl; 25-125 mM), all agonists were prepared in Ringer's solution. Between tests, the vasculatures were infused with Ringer's solution alone, during which time the perfusion pressure returned to basal values. A recovery period of at least $30 \mathrm{~min}$ was allowed between each agonist.

\section{Statistical analyses}

BP, HR and activity Basal BP parameters (SBP, DBP, MAP, PP and HR) and activities for each prenatal treatment (VEH or DEX) and gender, are shown in Table 2A (means \pm S.D). Data are calculated for each rat as an average over 3 days of telemetry recording. Statistical analysis of the data was by multivariate repeated measures MANOVA (with prenatal treatment, gender and light/dark period as dependent variables, and rat identification number/representative of each litter and time of day as random variables) which was carried out on the raw BP data for each rat and significance values for each dependent variable, together with interactions between variables are shown in Table 2 .

Values following drug treatment (amphetamine) were analysed by three-way ANOVA with prenatal treatment, amphetamine treatment and gender as variables, followed by Dunnett's post hoc test. Statistical significance was assumed at a value of $P<0 \cdot 05$.

Vascular studies All data are mean \pm s.E.M. For each mesenteric preparation, the maximal response and the concentration of agonist required for a $50 \%$ response $\left(\mathrm{EC}_{50}\right)$ were determined. Differences in the mean $\log \mathrm{EC}_{50}$ and maximal response values between VEH- and DEX-treated offspring mesenteric vasculatures were compared using Student's unpaired $t$-test. Data were further analysed by two-way ANOVA (prenatal treatment $X$ dose of agonist); results were considered significant when $P<0 \cdot 05$.

\section{Results}

\section{Gestational weight gain, birth phenotype and catch-up growth}

DEX administration throughout the final week of gestation resulted in a significant reduction in maternal weight gain, with no differences noted in the length of gestation, litter size, ratio of male to female pups born or pup viability (Table 1 ). Consistent with previous studies, DEX caused a significant reduction in the birth weight of offspring, which was observed to the same degree in both male and female pups (O'Regan et al. 2004). By weaning (postnatal day 21) and throughout adult life, the body weights of male and female offspring, treated with VEH or DEX were similar, that is, full

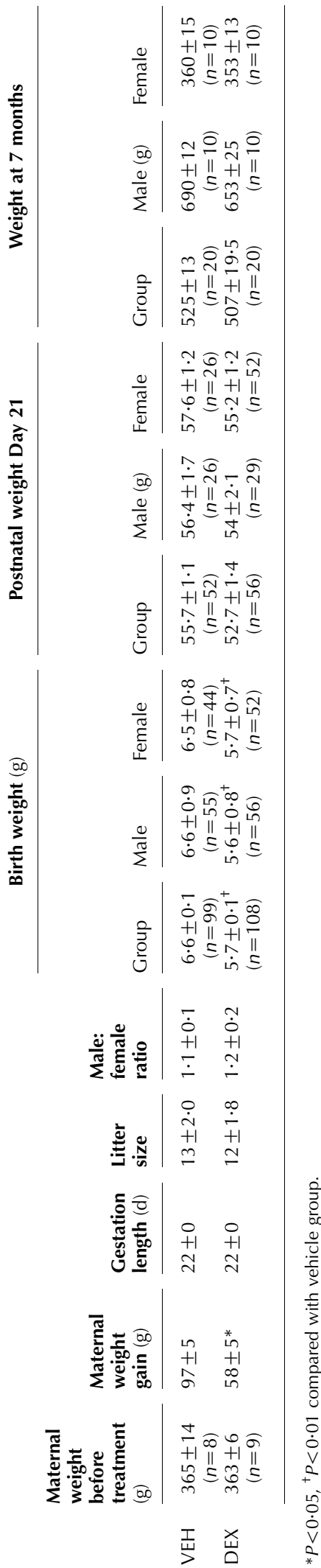

Journal of Endocrinology (2008) 196, 343-352 
catch-up growth had occurred (Table 1). Kidney size was not apparently altered by prenatal glucocorticoid treatment in either males (VEH: 0.005 $\pm 0 \cdot 0002 \mathrm{~g} / \mathrm{g}$ bwt, $n=7$ and DEX: $0 \cdot 0051 \pm 0 \cdot 00014 \mathrm{~g} / \mathrm{g}$ bwt, $n=5$ ) or females (VEH: $0 \cdot 00535 \pm 0 \cdot 00011 \mathrm{~g} / \mathrm{g}$ bwt, $n=5$ and DEX: 0.00495 \pm $0 \cdot 000177 \mathrm{~g} / \mathrm{g}<0 \cdot 001$ bwt, $n=6)$.

\section{Radiotelemetric monitoring of offspring BP, HR and activity under basal conditions}

$\mathrm{BP}, \mathrm{HR}$ and activity showed the expected sex variations and circadian variation in male and female offspring of both the prenatal treatment groups with the highest BP (MAP, SBP and DBP), HR and activity levels in the dark phase and lowest values during the light phase (Table 2 and Figs 1 and 2). Contrary to previous reports using indirect (tail cuff) and direct but stressful (carotid cannulation) methods to assess BP, both male and female DEX offspring showed basal hypotension with lower SBP, DBP, PP and HR compared with VEH rats (Figs 1 and 2 and Table 2), which was not dependent on whether the measurements were taken in the active, dark phase or the quiescent, light phase. However, there was a significant interaction between BP parameters and gender (Table 2), greater effects of prenatal treatment (PNT) being apparent in the males.

It was also observed that the DEX rats were less active than the VEH controls (Table 2), this effect was greater in the females compared with the males (interaction of PNT and gender, $P<0.001)$ and was observed mostly in the active, dark phase of the $24 \mathrm{~h}$ (interaction of PNT and day/night phase, $P<0 \cdot 001)$. The reduced activity of the DEX rats may contribute to the observed hypotension.

Table 2 (A) Blood pressure parameters measured under basal conditions in adult offspring of VEH- and dexamethasone (DEX)-treated dams. (B) Table of $P$ values resulting from MANOVA of telemetry data in A. Dependent variables are prenatal treatment (VEH or DEX), gender and day or night measurements. Results are mean \pm s.D. (number of observations), from all data collected over 72 -h period for each rat

\section{(A) Telemetry data}

Systolic $(\mathrm{mmHg})$

Av daily BP

$A v B P$ in light phase

$A v$ BP in dark phase

Diastolic $(\mathrm{mmHg})$

Av daily BP

$A v B P$ in light phase

$A v B P$ in dark phase

MAP $(\mathrm{mmHg})$

Av daily BP

$A v B P$ in light phase

Av BP in dark phase

Pulse pressure $(\mathrm{mmHg})$

Av daily PP

$A v$ PP in light phase

Av PP in dark phase

Heart Rate (beats/min)

Av daily $H R$

Av HR in light phase

Av HR in dark phase

Activity (arbitrary units)

Av daily activity

Av activity in light phase

Av activity in dark phase
VEH 0

\begin{tabular}{c} 
VEH o \\
\hline \\
$144 \cdot 5 \pm 10 \cdot 6(750)$ \\
$141 \cdot 7 \pm 9 \cdot 5(390)$ \\
$147 \cdot 6 \pm 11 \cdot 0(360)$ \\
$106 \cdot 1 \pm 9 \cdot 8(750)$ \\
$103 \cdot 4 \pm 8 \cdot 6(390)$ \\
$109 \cdot 0 \pm 10 \cdot 2(360)$ \\
$118 \cdot 9 \pm 10 \cdot 6(750)$ \\
$116 \cdot 1 \pm 8 \cdot 7(390)$ \\
$121 \cdot 9 \pm 10 \cdot 3(360)$ \\
$38 \cdot 5 \pm 3 \cdot 9(750)$ \\
$38 \cdot 3 \pm 3 \cdot 7(390)$ \\
$38 \cdot 7 \pm 4 \cdot 2(360)$ \\
$339 \cdot 3 \pm 60 \cdot 4(750)$ \\
$306 \cdot 7 \pm 44 \cdot 1(390)$ \\
$374 \cdot 6 \pm 55 \cdot 7(360)$ \\
$2 \cdot 88 \pm 2 \cdot 81(745)$ \\
$1 \cdot 41 \pm 1 \cdot 73(385)$ \\
$4 \cdot 46 \pm 2 \cdot 88(360)$ \\
\end{tabular}

DEX 0

$140 \cdot 2 \pm 15 \cdot 2(717)$

$138 \cdot 3 \pm 16 \cdot 2(386)$

$142 \cdot 5 \pm 13 \cdot 7(331)$

$103 \cdot 3 \pm 12 \cdot 8(717)$

$101 \cdot 6 \pm 13 \cdot 4(386)$

$105 \cdot 3 \pm 11 \cdot 4(331)$

$115 \cdot 6 \pm 15 \cdot 5(717)$

$113 \cdot 9 \pm 14 \cdot 4(386)$

$117 \cdot 7 \pm 12 \cdot 1(331)$

$$
\begin{aligned}
& 36 \cdot 9 \pm 3 \cdot 7(717) \\
& 36 \cdot 7 \pm 3 \cdot 8(386) \\
& 37 \cdot 2 \pm 3 \cdot 6(331)
\end{aligned}
$$

$349 \cdot 2 \pm 62 \cdot 3(717)$

$323 \cdot 1 \pm 53 \cdot 3(386)$

$379 \cdot 6 \pm 58 \cdot 4(331)$

$2 \cdot 51 \pm 2 \cdot 50(745)$

$1 \cdot 29 \pm 1 \cdot 58(385)$

$3 \cdot 82 \pm 2 \cdot 64(360)$
VEH +

$138 \cdot 3 \pm 10 \cdot 4(450)$

$135 \cdot 2 \pm 10 \cdot 2(234)$

$141 \cdot 6 \pm 9 \cdot 5$ (216)

$101 \cdot 5 \pm 8 \cdot 9$ (450)

$99 \cdot 4 \pm 8 \cdot 4(234)$

$103 \cdot 8 \pm 8 \cdot 9(216)$

$113 \cdot 8 \pm 9 \cdot 2(450)$

$111 \cdot 3 \pm 8 \cdot 9(234)$

$116 \cdot 4 \pm 8 \cdot 9(216)$

$$
\begin{aligned}
& 36 \cdot 8 \pm 4 \cdot 0(450) \\
& 35 \cdot 8 \pm 3 \cdot 8(234) \\
& 37 \cdot 8 \pm 4 \cdot 08(216)
\end{aligned}
$$

$366 \cdot 9 \pm 64 \cdot 2(450)$

$335 \cdot 7 \pm 54 \cdot 8(234)$

$400 \cdot 7 \pm 56 \cdot 0(216)$

$4 \cdot 85 \pm 4 \cdot 38(447)$

$2 \cdot 53 \pm 2 \cdot 90(231)$

$7 \cdot 32 \pm 4 \cdot 34(216)$
DEX

$129 \cdot 7 \pm 12 \cdot 7(749)$

$126 \cdot 6 \pm 11 \cdot 8(390)$

$133 \cdot 1 \pm 12 \cdot 8$ (359)

$99 \cdot 4 \pm 13 \cdot 0(749)$

$96 \cdot 3 \pm 12 \cdot 0(390)$

$102 \cdot 7 \pm 13 \cdot 3(360)$

$109 \cdot 4 \pm 4 \cdot 7(749)$

$106 \cdot 4 \pm 11 \cdot 7$ (390)

$112 \cdot 7 \pm 12 \cdot 9$ (359)

$30 \cdot 4 \pm 5 \cdot 9(749)$

$30 \cdot 3 \pm 5 \cdot 1$ (390)

$30 \cdot 4 \pm 5 \cdot 9$ (359)

$366 \cdot 0 \pm 62 \cdot 2(750)$

$332 \cdot 1 \pm 48 \cdot 4(390)$

$398 \cdot 7 \pm 56 \cdot 5$ (359)

$3 \cdot 50 \pm 3 \cdot 74(750)$

$1 \cdot 70 \pm 2 \cdot 25$ (385)

$5 \cdot 42 \pm 4 \cdot 05$ (360)

(B) $P$ values resulting from MANOVA of telemetry data

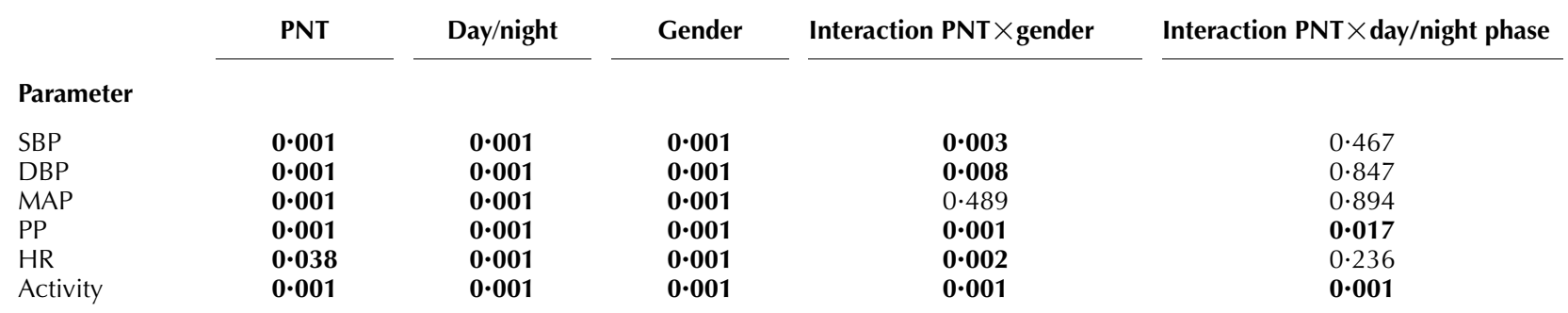

Bold numbers indicate significance $(P<0 \cdot 05)$ of dependent variables and interactions of these variables. SBP, systolic blood pressure; DBP, diastolic blood pressure; MAP, mean arterial pressure; $\mathrm{PP}$, pulse pressure; $\mathrm{HR}$, heart rate. 

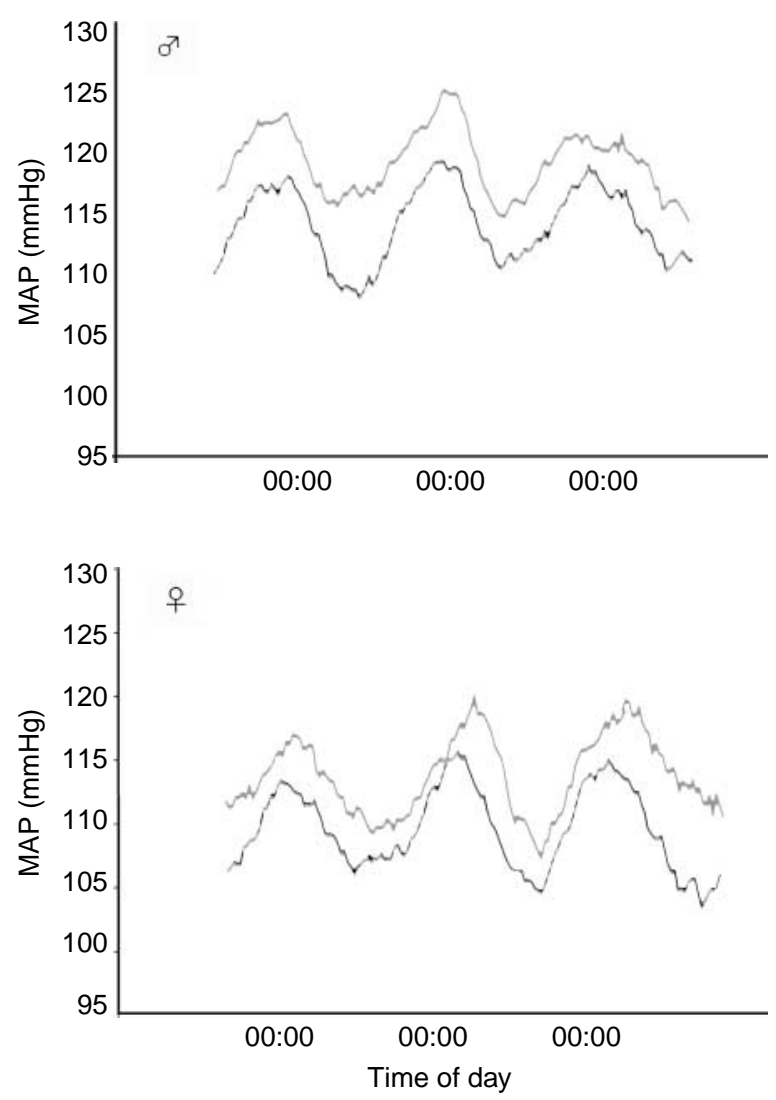

Figure 1 Basal mean arterial blood pressure (MAP) in male and female offspring exposed to VEH (grey) or DEX (black) during the last week of gestation. Data are expressed as $6-\mathrm{h}$ rolling averages over 3 days for each treatment group. $n=4-5$ per group.

\section{Haemodynamic and activity responses to graded stress}

In utero exposure to DEX has been shown to cause a lifelong elevation in basal BP when measured by tail-cuff plethysmography and carotid cannulation. An exaggerated stress response to these measurement techniques could account for apparent hypertension. As shown in Fig. 3 (A, B and E), male, prenatal DEX-treated offspring were exquisitely sensitive to stress, displaying graded hypertensive responses when disturbed by a researcher entering their room and when restrained. Even weighing elicited a hypersensitive response in DEX-treated offspring (change in SBP; VEH $10 \pm 2 \mathrm{mmHg}$ and DEX $19 \pm 3 \mathrm{mmHg} ; P<0 \cdot 05)$. Moreover, DEX-treated offspring start with a reduced MAP compared with vehicle controls (Fig. 3A and B) and maintain their stress-induced hypertension for longer once released from restraint (Fig. 3E), and after weighing (change in SBP 5-min post-weighing; VEH $7 \pm 5 \mathrm{mmHg}$ and DEX $23 \pm 5 \mathrm{mmHg} ; \quad P<0 \cdot 05$ ). DEX-treated offspring further displayed significantly greater increases in HR in response to weighing (VEH $117 \pm 17 \mathrm{bpm}$ and DEX $156 \pm 25 \mathrm{bpm} ; P<0 \cdot 05$ ), and restraint (VEH $86 \pm 11 \mathrm{bpm}$ and DEX $136 \pm 19 \mathrm{bpm} ; P<0 \cdot 05)$. The greater tachycardia on disturbance of prenatal DEX offspring was not
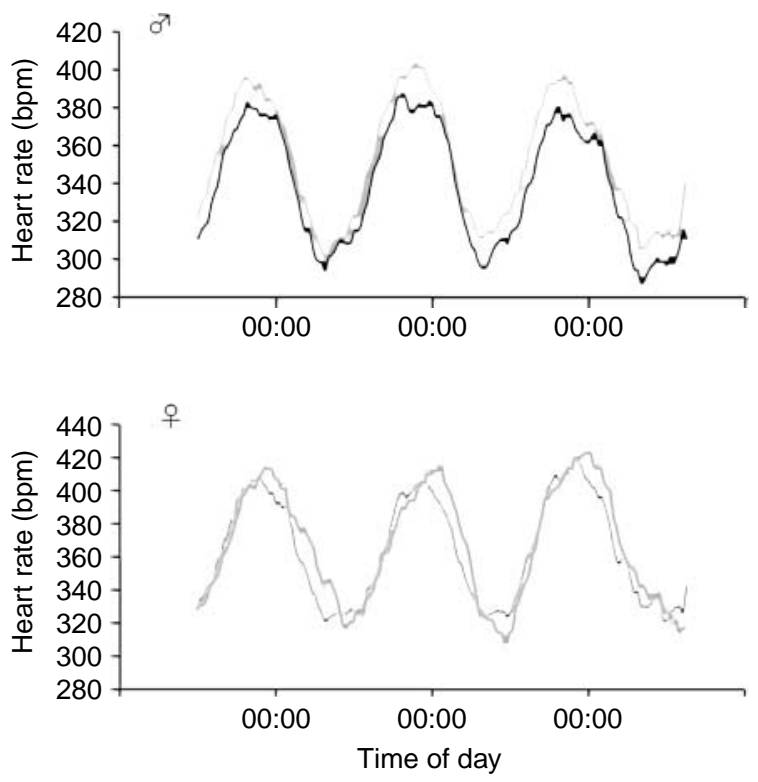

Figure 2 Basal heart rate patterns in male and female offspring exposed to VEH (grey) or DEX (black) during the last week of gestation. Data are expressed as 6-h rolling averages over 3 days. $n=4-5$ per group.

associated with changes in activity (weighing: VEH $5 \cdot 2 \pm 1$ AU, DEX $5 \pm 1$ AU and restraint: VEH $4 \cdot 8 \pm 1 \cdot 2$ AU, DEX $4 \cdot 6 \pm 1 \cdot 8 \mathrm{AU})$. Although there was a significant response in $\mathrm{BP}$ to stress in all females, there was no significant difference between the VEH- and DEX-treated offspring in response to disturbance or restraint stress but the recovery period after stress shows DEX females take longer to return basal levels of MAP following restraint (Fig. 3C-E).

Prenatal DEX causes exaggerated hypertensive responses to catecholaminergic stimulation

To assess the role of the SNS in mediating this stress-induced hypertension, we administered a low dose of D-amphetamine, to induce catecholamine release. While the DEX-treated offspring showed lower basal MAPs prior to amphetamine administration (Fig. 4A and B), they showed significantly greater increases in MAP and HR when treated with the drug compared with controls (amphetamine treatment $F(1,20)=21 \cdot 54, P=0 \cdot 0002$; prenatal treatment $F(1,20)=13 \cdot 19, P=0 \cdot 0017$; Fig. 4A-C). When the data were separated into male and female responses, it was demonstrated that there was no indication of a sex-specific effect $(F(1,20)=0 \cdot 52, P=0 \cdot 48$; Fig. 4C).

\section{Responsiveness of mesenteric vasculature to $N A, A V P$ and $K C L$}

To examine further the basis for increased responsivity to catecholaminergic stimulation in DEX-exposed offspring, resistance (mesenteric) vessels were perfused ex vivo (Fig. 5A-C). Basal perfusion pressures were similar in the two groups of rats. Infusion of all agonists caused a concentration- 


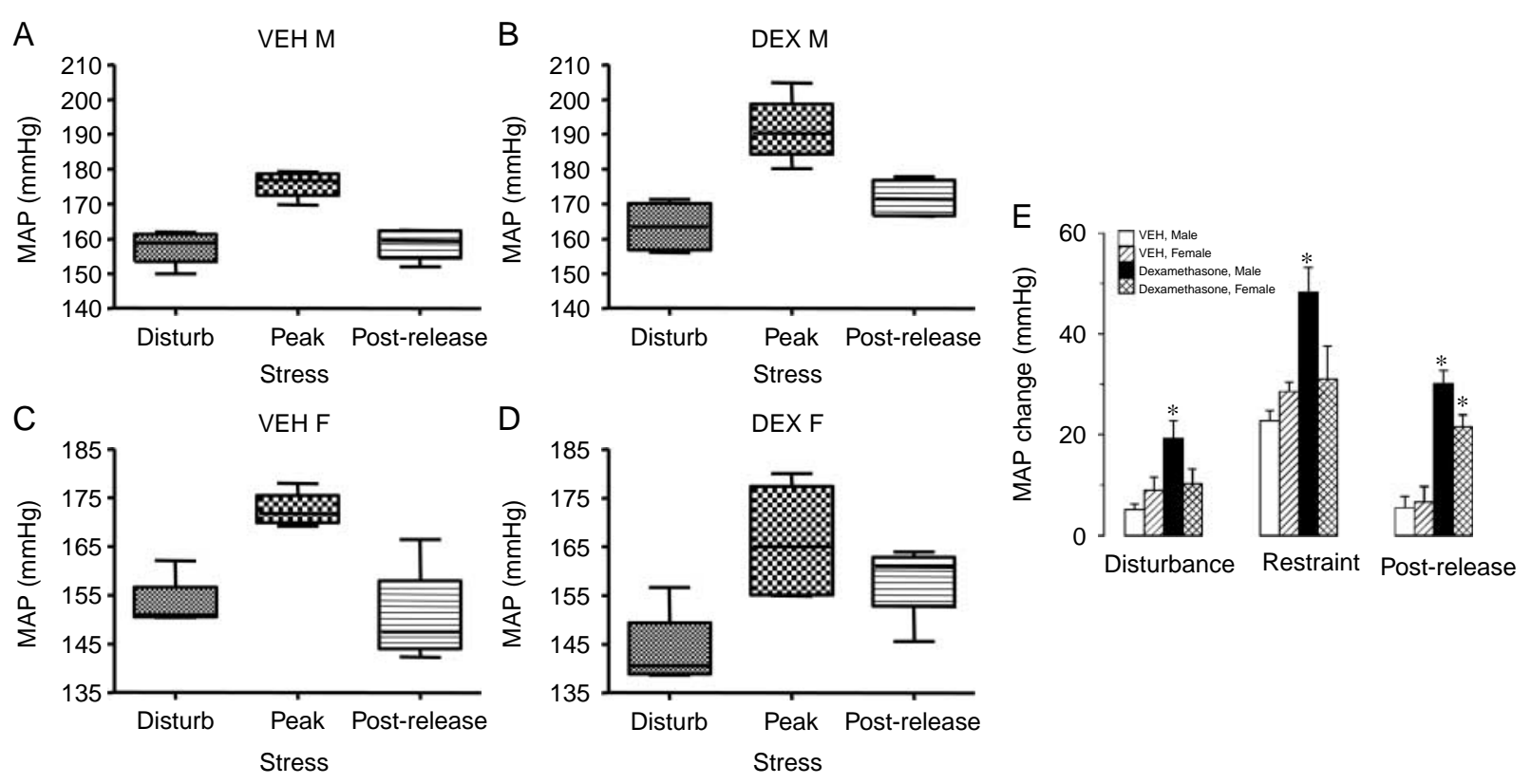

Figure 3 Box-Whisker plots depicting MAP in response to disturbance, restraint and at 15 -min post-restraint ( $n=4-5$ per group) in (A) male offspring from VEH-treated dams, (B) male offspring from DEX-treated dams, (C) female offspring from VEH-treated dams and (E) female offspring from DEX-treated dams, (E) shows stress-induced MAP changes in prenatal VEH- and DEX-treated offspring, following disturbance, restraint and at 15 -min post-restraint (mean \pm S.E.M., $n=4-5$ per group). ${ }^{*} P<0 \cdot 05$ compared with vehicle group.

dependent increase in perfusion pressures, with plateaux reached in both groups at $5 \mu \mathrm{M}$ for NA and $10 \mathrm{nM}$ for AVP. However, tissues from DEX-treated male offspring were significantly more responsive (the curves from DEX-treated offspring were significantly different from VEH controls; Fig. 5) and the $V_{\max }$ (indicative of number of receptors) was higher in the DEX group in response to NA in both sexes (male VEH: $305 \pm 13 \mathrm{mmHg}$; male DEX: $360 \pm 4 \mathrm{mmHg} ; P=0 \cdot 004$; $t$-test. Female VEH: $292 \pm 5$ mmHg; female DEX: $345 \pm 7$ mmHg; $P=0 \cdot 001)$.

\section{Female offspring}

Several reports suggest that prenatal 'programming' phenotypes are sexually dimorphic, so the perfusion studies were repeated in females. Similar basal perfusion pressures were noted in the two prenatal treatment groups. NA caused a concentration-dependent increase in perfusion pressures, with plateaux reached at $2 \mu \mathrm{M}$ in both treatment groups (Fig. 5D). However, the mesenteric vasculatures from DEXtreated offspring were significantly more responsive to NA, (as analysed by two-way ANOVA), even though the maximal contraction (VEH $344 \pm 40 \mathrm{mmHg}$ versus DEX $373 \pm$ $30 \mathrm{mmHg} ; \quad P=0.16$ ) and $\mathrm{EC}_{50}$ (vehicle $0.43 \pm 0.02 \mu \mathrm{M}$ versus DEX $0.39 \pm 0.03 \mu \mathrm{M} ; P=0.16)$ values were similar for both treatment groups. DEX treatment did not affect the pattern of responses to either AVP or $\mathrm{KCl}$. Maximal responses in both groups were achieved at $5 \mathrm{nM}$ AVP and $125 \mathrm{mM} \mathrm{KCl}$ (data not shown).
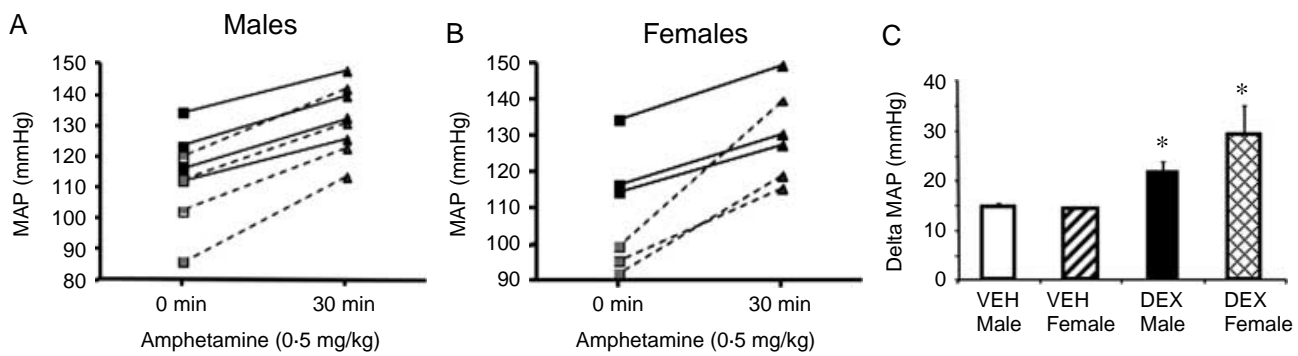

Figure 4 Line plots indicating MAP from individual rats 0 and $30 \mathrm{~min}$ following amphetamine $(0.5 \mathrm{mg} / \mathrm{kg})$ in (A) male and (B) female offspring from either VEH (black symbols with solid line) or DEX (grey symbols with dotted line) dams. (C) $\Delta$-MAP response to amphetamine $(0.5 \mathrm{mg} / \mathrm{kg}$; i.p.), in male and female offspring of VEHand DEX-treated dams. Results are mean \pm s.E.M., three-way ANOVA (prenatal treatment $\times$ gender $\times$ postnatal drug), $n=7$ (4 $\delta^{*}$ and 3 $\%$ ); ${ }^{*} P<0 \cdot 05$ compared with vehicle group. 

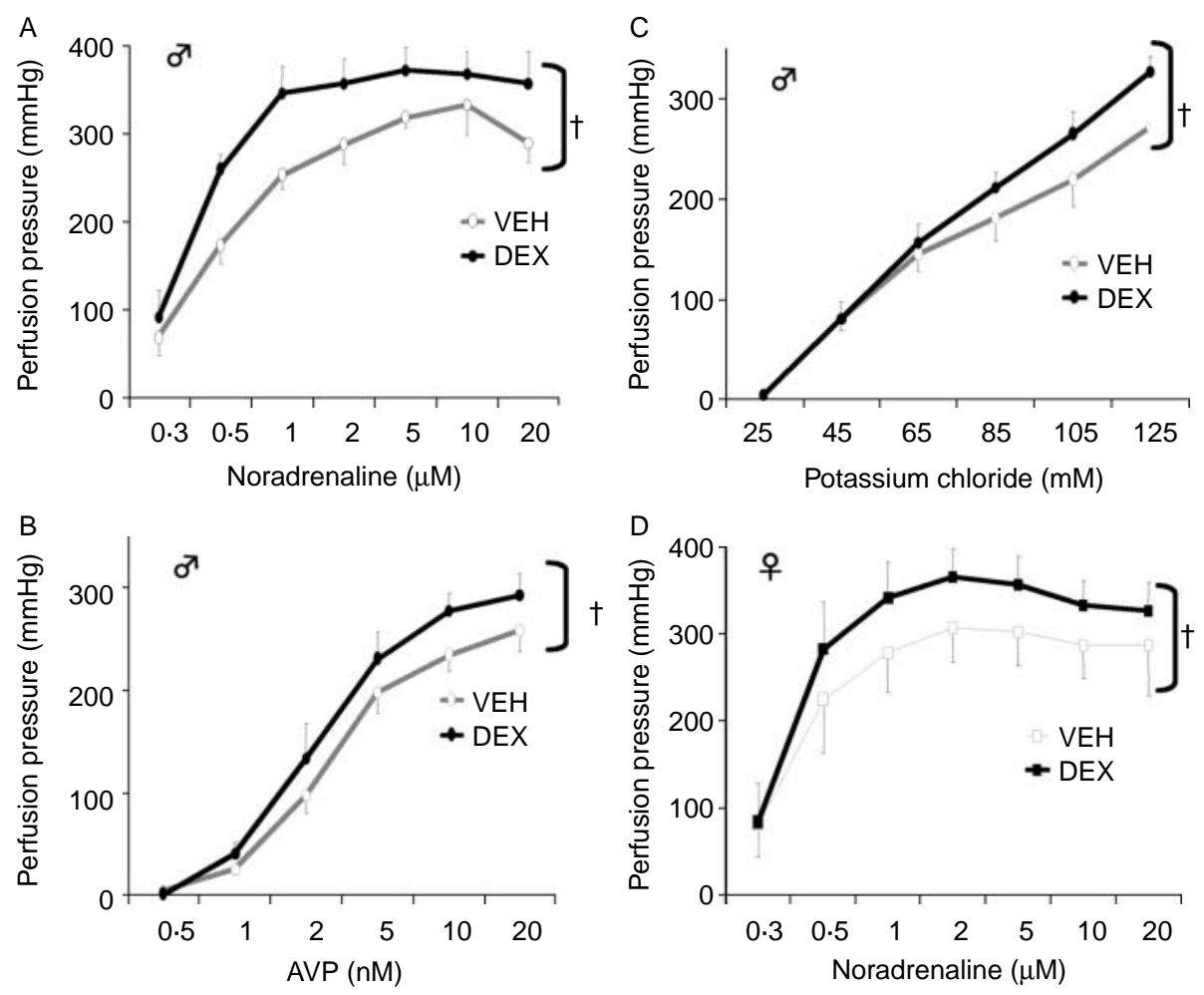

Figure 5 Male offspring dose-response curves to (A) noradrenaline, (B) vasopressin, (C) potassium chloride and (D) female offspring dose-response curve to noradrenaline, in the isolated mesenteric vasculature from VEH- and DEX-treated rats. Results are mean \pm s.E.M., $n=6$ per group. ${ }^{+} P<0 \cdot 01$ compared with vehicle group.

\section{Discussion}

The striking novel finding of this study is that prenatal DEX results in lower basal $\mathrm{BP}$ in the male and female adult offspring; with the commonly expected hypertensive phenotype only being noted when these offspring are subjected to a stressor, after which they exhibit a prolonged and excessive hypertensive response. These exaggerated hypertensive responses are mediated by alterations in the responsivity of the SNS, being further exaggerated by promotion of catecholamine release. Additionally, DEX-treated offspring display greater sensitivity to catecholamines, and only in males other vasoconstrictors, in resistance (mesenteric) vasculature.

Unexpectedly, over many days of recording undisturbed rats in their home cages, prenatal DEX-exposed adult rats showed lower BP than controls. This contrasts with both tail cuff plethysmography and direct carotid cannulation data in this model (Levitt et al. 1996) and in other models of 'fetal programming' (Woodall et al. 1996, Langley-Evans 1997, Woods 2006) most of which have generally employed techniques which involve stressful preheating of the tail and/ or physical restraint or short-term recovery from anaesthesia. Indeed, several studies have documented by telemetry the stressinduced hypertension observed following restraint or using the tail-cuff protocol (Gross \& Luft 2003, Whitesall et al. 2004, D'Angelo et al. 2005, Kurtz et al. 2005), confirming the telemetry technique as the 'gold standard' for BP recording. In our study, radiotelemetric measurements were recorded 1 week after implantation of intra-arterial cannulae to allow complete recovery from established effects of surgery. Previous studies have used telemetry to determine BP in other models of fetal programming following maternal undernutrition (Tonkiss et al. 1998, Khan et al. 2003, Fernandez-Twinn et al. 2006) or uterine artery ligation (Jansson \& Lambert 1999). BP differences by telemetry have generally been slight, with normotension or at most mild hypertension, compared with more overt hypertension using indirect techniques. The quite clear-cut lower basal $\mathrm{BP}$ seen here in males and females in both active and quiescent phases may therefore reflect specific effects of prenatal glucocorticoid excess compared with other manipulations, even though it is acknowledged that glucocorticoid programming is combined with an effect on food intake and maternal weight (present data; Levitt et al. 1996, Welberg et al. 2001, Woods 2006). However, short-term measurements of BP, even over a few hours, failed to attribute statistical significance between the prenatally treated groups in this study, emphasizing the statistical power of the telemetric BP measurements, but highlighting potential differences between studies and analysis of the data. 
The hypotension observed in the DEX rats may in part be attributable to decreased activity in DEX rats compared with VEH. However, activity differences are greater in the female DEX rats (compared with female VEH rats), while BP parameters of hypotension are greater in the male DEX rats indicating that several parameters may be altered to mediate the $\mathrm{BP}$ changes and that these mechanisms may be sex specific.

Merely entering the room in which the rats were housed was sufficient to drive hypertension selectively in male, prenatal DEX-exposed offspring. When further subjected to a moderate stressor (weighing) and the more severe restraint stress the hypertensive responses of the male DEX-treated offspring were significantly augmented, suggesting increased sensitivity to environmental stress. An increased reactivity to stressful environmental stimuli may lead to established hypertension through frequent transient $\mathrm{BP}$ elevations (Folkow et al. 1978). Whether or not the prenatal DEXexposed offspring will eventually become permanently hypertensive warrants further study, as true life consists of a constant series of 'stressful situations' that have to be dealt with, and this is not mimicked in undisturbed laboratory animals. Indeed, the DEX-treated offspring maintained their hypertension long after the removal of each stressor. Interestingly, offspring of malnourished dams display a greater hypertensive response to stress (ammonia odour) echoing the clear stressresponsive hypertension shown here in prenatal glucocorticoid programming (Tonkiss et al. 1998). It is therefore tempting to speculate that prenatal glucocorticoid programming of exaggerated cardiovascular responses to stress may be the fundamental change in these models, with permanent hypertension a secondary phenomenon dependent upon the postnatal environment and its challenges. This would parallel the emerging concepts of amplification of the low birth weight baby metabolic phenotype by postnatal caloric excess (Ozanne \& Nicholas Hales 2005). Moreover, lower basal BP but enhanced responses to stress align perhaps better with concepts of adaptive advantages to the predicted (stressful) postnatal environment of a stressed pregnancy than merely constant hypertension, which has few apparent benefits.

DEX-treated offspring had higher HR with stress, a marker, although indirect, of increased sympathetic drive. The cardiodynamic responses to catecholamine release with amphetamine (or catecholamine depletion with reserpine, O'Regan unpublished results) strongly support this notion of a more responsive SNS in DEX-programmed adult rats. Amphetamine caused an exaggerated increase in BP in DEX-treated offspring compared with controls and reserpine abolished BP differences between DEX and VEH groups basally and in response to stress. The SNS participates in several stress responses, even in fetal life (McMillen et al. 2001) and therefore prenatal exposure to various stressors might affect the development of sympathetic innervation or its regulation. Epidemiological evidence of HR variability in infants demonstrates a positive correlation of this index of sympathetic activity with low birth weight, suggesting that decreased fetal growth is associated with a dysfunctional autonomic nervous system which may play a role in programming of BP (Massin et al. 2001). Indeed in rats, the offspring of prenatal DEX-treated dams have increased NA turnover in central brain regions concerned with BP control (Slotkin et al. 1992), however, cardiac $\beta$-adrenergic responses are blunted in low protein diet-induced-programmed rats (Fernandez-Twinn et al. 2006). In distinct prenatal rat models, gestational nicotine impairs the maturation of both central and peripheral catecholaminergic pathways (Navarro et al. 1990) and hypoxia alters development of sympathetic centres involved in BP regulation (Peyronnet et al. 2002), effects which persist into adulthood. Similarly, ligation of the umbilical artery alters SNS activity in newborn sheep (Oyama et al. 1992) and adult female rat offspring (Jansson \& Lambert 1999). Taken together, these data indicate that diverse challenges in utero alter the development and function of the adult SNS. A recent study of low birth weight adult humans proposed that their lower resting muscle sympathetic nerve activities were a function of altered SNS development (Weitz et al. 2003).

Sex effects on BP regulation in prenatal-programming models have been shown in a few studies (Kind et al. 2002, O'Regan et al. 2004), but not others (Langley-Evans et al. 1996, Woods \& Weeks 2005), although the hypertension may be generated by sex-specific mechanisms (McMullen \& Langley-Evans 2005a,b). Indeed in humans, females have been shown to have more efficient regulation of SNS pathways, making them less susceptible to hypertension (Hinojosa-Laborde et al. 1999). However, in this study, we show similar effects on BP in males and females, but the magnitude of hypotension and a greater stress-induced hypertension is observed in males. The response to catecholamine release was similar in both sexes. Therefore, further studies will be required to tease out the mechanisms underpinning the sex-specific responsivity in this programming model.

Whatever the changes in SNS drive, DEX-treated offspring showed greater in vitro mesenteric pressor responses to NA in both male and females suggesting increased tissue sensitivity. There were also greater pressor responses to AVP and a depolarizing potassium solution in males only. Similar results were obtained in a study looking at female offspring from mothers treated with DEX throughout pregnancy (Hadoke et al. 2006). The in vitro perfusion preparation used in these studies was separated from other in vivo systems (e.g. circulating angiotensin II, endothelin), suggesting that a change in receptor binding or alterations in the production of local vasorelaxants/constrictors underlies the increased vascular sensitivity. Glucocorticoids may regulate the synthesis of vasoactive compounds, such as prostaglandins or nitric oxide, which in turn modulate peripheral vascular reactivity. Indeed, inhibition of nitric oxide synthesis (Wallerath et al. 1999) and decreased levels of both prostaglandin and its mediator adenylate cyclase (Handa et al. 1984) have been demonstrated in rats with adult DEXinduced hypertension. Similarly, increased mesenteric vasculature sensitivity to NA has been observed in rats treated as adults with low doses of DEX (Russo et al. 1990). Whether the effects are due to the known modest elevations of 
corticosterone in DEX-programmed rats (Levitt et al. 1996, Welberg et al. 2001) or reflect primary developmental effects on the mesenteric vasculature that persist into adult life remains uncertain. The gender differences in mesenteric vasculature responses of DEX-treated offspring to both AVP and $\mathrm{KCl}$ are intriguing, and could possibly reflect changes in vascular reactivity during the reproductive cycle (Dalle Lucca et al. 2000), and the effect of sex steroids on vascular smooth muscle sensitivity (Garcia-Villalon et al. 1996). Interestingly, gender has previously been demonstrated to have no effect on the sensitivity to NA in both the rat tail artery and aorta (Li \& Duckles 1994, Fulton \& Stallone 2002).

The present study provides novel and exciting information regarding the nature and mechanisms of glucocorticoidinduced alterations in postnatal BP. As the prenatal glucocorticoid exposure models extend our understanding of the fetal origins phenomena, it is clear that there is a need for replication and extended studies in humans. Only then, will we be better equipped to understand both the immediate and long-term consequences of antenatal glucocorticoid treatment.

\section{Acknowledgements}

Expert animal assistance was provided by Gillian Brooker for the surgical implantation of telemetric devices, and by Willy Mungall. This study was supported by a Wellcome Trust CVRI studentship (D O'R), the Wellcome Trust (J R S and $\mathrm{M} \mathrm{C} \mathrm{H}$ ) and the Medical Research Council (C J K). The authors declare that there is no conflict of interest that would prejudice the impartiality of this scientific work.

\section{References}

Anderson NH, Devlin AM, Graham D, Morton JJ, Hamilton CA, Reid JL, Schork NJ \& Dominiczak AF 1999 Telemetry for cardiovascular monitoring in a pharmacological study: new approaches to data analysis. Hypertension 33 248-255.

Barker DJ 1990 The fetal and infant origins of adult disease. British Medical Journal 3011111.

Barker DJ 1999 Fetal origins of cardiovascular disease. Annals of Medicine 31(Suppl 1) 3-6.

Barker DJ 2003 The developmental origins of adult disease. European Journal of Epidemiology 18 733-736.

Benediktsson R, Lindsay RS, Noble J, Seckl JR \& Edwards CR 1993 Glucocorticoid exposure in utero: new model for adult hypertension. Lancet 341 339-341.

Bian XP, Seidler FJ \& Slotkin TA 1992 Promotional role for glucocorticoids in the development of intracellular signalling: enhanced cardiac and renal adenylate cyclase reactivity to beta-adrenergic and non-adrenergic stimuli after low-dose fetal dexamethasone exposure. Journal of Developmental Physiology 17 289-297.

Bian X, Seidler FJ \& Slotkin TA 1993 Fetal dexamethasone exposure interferes with establishment of cardiac noradrenergic innervation and sympathetic activity. Teratology 47 109-117.

Curhan GC, Willett WC, Rimm EB, Spiegelman D, Ascherio AL \& Stampfer MJ 1996a Birth weight and adult hypertension, diabetes mellitus, and obesity in US men. Circulation 94 3246-3250.
Curhan GC, Chertow GM, Willett WC, Spiegelman D, Colditz GA, Manson JE, Speizer FE \& Stampfer MJ $1996 b$ Birth weight and adult hypertension and obesity in women. Circulation 94 1310-1315.

Dalle Lucca JJ, Adeagbo AS \& Alsip NL 2000 Influence of oestrous cycle and pregnancy on the reactivity of the rat mesenteric vascular bed. Human Reproduction 15 961-968.

D’Angelo G, Elmarakby AA, Pollock DM \& Stepp DW 2005 Fructose feeding increases insulin resistance but not blood pressure in SpragueDawley rats. Hypertension $\mathbf{4 6}$ 806-811.

Fall CH, Stein CE, Kumaran K, Cox V, Osmond C, Barker DJ \& Hales CN 1998 Size at birth, maternal weight, and type 2 diabetes in South India. Diabetic Medicine 15 220-227.

Fernandez-Twinn DS, Ekizoglou S, Wayman A, Petry CJ \& Ozanne SE 2006 Maternal low protein diet programs cardiac beta-adrenergic response and signalling in 3 month old male offspring. American Journal of Physiology 291 R429-R436.

Folkow B, Hallback MIL, Genest J, Koiw E \& Kuchel O 1978 Physiopathology of spontaneous hypertension in rats. In Hypertension: Pathophysiology and Treatment, pp 507-529. Eds J Genest, E Koiw \& O Kuchel. New York: MacGraw Hill.

Fulton CT \& Stallone JN 2002 Sexual dimorphism in prostanoidpotentiated vascular contraction: roles of endothelium and ovarian steroids. American Journal of Physiology 283 H2062-H2073.

Garcia-Villalon AL, Buchholz JN, Krause DN \& Duckles SP 1996 Sex differences in the effects of 17 beta-estradiol on vascular adrenergic responses. European Journal of Pharmacology 314 339-345.

Gross V \& Luft FC 2003 Exercising restraint in measuring blood pressure in conscious mice. Hypertension 41 879-881.

Hadoke PW, Lindsay RS, Seckl JR, Walker BR \& Kenyon CJ 2006 Altered vascular contractility in adult female rats with hypertension programmed by prenatal glucocorticoid exposure. Journal of Endocrinology 188 435-442.

Handa M, Kondo K, Suzuki H \& Saruta T 1984 Dexamethasone hypertension in rats: role of prostaglandins and pressor sensitivity to norepinephrine. Hypertension 6 236-241.

Hinojosa-Laborde C, Chapa I, Lange D \& Haywood JR 1999 Gender differences in sympathetic nervous system regulation. Clinical and Experimental Pharmacology and Physiology 26 122-126.

Huff RA, Seidler FJ \& Slotkin TA 1991 Glucocorticoids regulate the ontogenetic transition of adrenergic receptor subtypes in rat liver. Life Sciences 48 1059-1065.

Jansson T \& Lambert GW 1999 Effect of intrauterine growth restriction on blood pressure, glucose tolerance and sympathetic nervous system activity in the rat at 3-4 months of age. Journal of Hypertension 17 1239-1248.

Khan IY, Taylor PD, Dekou V, Seed PT, Lakasing L, Graham D, Dominiczak AF, Hanson MA \& Poston L 2003 Gender-linked hypertension in offspring of lard-fed pregnant rats. Hypertension 41 168-175.

Kind KL, Simonetta G, Clifton PM, Robinson JS \& Owens JA 2002 Effect of maternal feed restriction on blood pressure in the adult guinea pig. Experimental Physiology 87 469-477.

Kreider ML, Aldridge JE, Cousins MM, Oliver CA, Seidler FJ \& Slotkin TA 2005 Disruption of rat forebrain development by glucocorticoids: critical perinatal periods for effects on neural cell acquisition and on cell signaling cascades mediating noradrenergic and cholinergic neurotransmitter/neurotrophic responses. Neuropsychopharmacology 30 1841-1855.

Kurtz TW, Griffin KA, Bidani AK, Davisson RL \& Hall JE 2005 Recommendations for blood pressure measurement in humans and experimental animals: part 2: blood pressure measurement in experimental animals: a statement for professionals from the Subcommittee of Professional and Public Education of the American Heart Association Council on High Blood Pressure Research. Arteriosclerosis, Thrombosis, and Vascular Biology 25 E22-E33.

Langdown ML, Smith ND, Sugden MC \& Holness MJ 2001 Excessive glucocorticoid exposure during late intrauterine development modulates the expression of cardiac uncoupling proteins in adult hypertensive male offspring. Pflugers Archiv 442 248-255. 
Langley-Evans SC 1997 Hypertension induced by foetal exposure to a maternal low-protein diet, in the rat, is prevented by pharmacological blockade of maternal glucocorticoid synthesis. Journal of Hypertension 15 537-544.

Langley-Evans SC, Phillips GJ, Benediktsson R, Gardner DS, Edwards CR, Jackson AA \& Seckl JR 1996 Protein intake in pregnancy, placental glucocorticoid metabolism and the programming of hypertension in the rat. Placenta 17 169-172.

Law CM, Egger P, Dada O, Delgado H, Kylberg E, Lavin P, Tang GH, von Hertzen H, Shiell AW \& Barker DJ 2001 Body size at birth and blood pressure among children in developing countries. International Journal of Epidemiology 30 52-57.

Levitt NS, Lindsay RS, Holmes MC \& Seckl JR 1996 Dexamethasone in the last week of pregnancy attenuates hippocampal glucocorticoid receptor gene expression and elevates blood pressure in the adult offspring in the rat. Neuroendocrinology 64 412-418.

Li Z \& Duckles SP 1994 Influence of gender on vascular reactivity in the rat. Journal of Pharmacology and Experimental Therapeutics 268 1426-1431.

Massin MM, Withofs N, Maeyns K \& Ravet F 2001 The influence of fetal and postnatal growth on heart rate variability in young infants. Cardiology 95 $80-83$.

McCance DR, Pettitt DJ, Hanson RL, Jacobsson LT, Knowler WC \& Bennett PH 1994 Birth weight and non-insulin dependent diabetes: thrifty genotype, thrifty phenotype, or surviving small baby genotype? British Medical Journal 308 942-945.

McGregor DD 1965 The effect of sympathetic nerve stimulation on vasoconstrictor responses in perfused mesenteric blood vessel of the rat. Journal of Physiology 177 21-30.

McMillen IC, Adams MB, Ross JT, Coulter CL, Simonetta G, Owens JA, Robinson JS \& Edwards LJ 2001 Fetal growth restriction: adaptations and consequences. Reproduction 122 195-204.

McMullen S \& Langley-Evans SC 2005a Maternal low-protein diet in rat pregnancy programs blood pressure through sex-specific mechanisms. American Journal of Physiology 288 R85-R90.

McMullen S \& Langley-Evans SC $2005 b$ Sex-specific effects of prenatal lowprotein and carbenoxolone exposure on renal angiotensin receptor expression in rats. Hypertension 46 1374-1380.

Navarro HA, Mills E, Seidler FJ, Baker FE, Lappi SE, Tayyeb MI, Spencer JR \& Slotkin TA 1990 Prenatal nicotine exposure impairs beta-adrenergic function: persistent chronotropic subsensitivity despite recovery from deficits in receptor binding. Brain Research Bulletin 25 233-237.

Nyirenda MJ, Lindsay RS, Kenyon CJ, Burchell A \& Seckl JR 1998 Glucocorticoid exposure in late gestation permanently programs rat hepatic phosphoenolpyruvate carboxykinase and glucocorticoid receptor expression and causes glucose intolerance in adult offspring. Journal of Clinical Investigation 101 2174-2181.

Nyirenda MJ, Welberg LA \& Seckl JR 2001 Programming hyperglycaemia in the rat through prenatal exposure to glucocorticoids-fetal effect or maternal influence? Journal of Endocrinology 170 653-660.

O’Regan D, Kenyon CJ, Seckl JR \& Holmes MC 2004 Glucocorticoid exposure in late gestation in the rat permanently programs gender-specific differences in adult cardiovascular and metabolic physiology. American Journal of Physiology 287 E863-E870.

Ortiz LA, Quan A, Zarzar F, Weinberg A \& Baum M 2003 Prenatal dexamethasone programs hypertension and renal injury in the rat. Hypertension 41 328-334.

Oyama K, Padbury J, Martinez A, Chappell B, Stein H \& Humme J 1992 Effects of fetal growth retardation on the development of central and peripheral catecholaminergic pathways in the sheep. Journal of Developmental Physiology 18 217-222.

Ozanne SE \& Nicholas Hales C 2005 Poor fetal growth followed by rapid postnatal catch-up growth leads to premature death. Mechanisms of Ageing and Development 126 852-854.

Padbury JF, Polk DH, Ervin MG, Berry LM, Ikegami M \& Jobe AH 1995 Postnatal cardiovascular and metabolic responses to a single intramuscular dose of betamethasone in fetal sheep born prematurely by cesarean section. Pediatric Research 38 709-715.
Peyronnet J, Dalmaz Y, Ehrstrom M, Mamet J, Roux JC, Pequignot JM, Thoren HP \& Lagercrantz H 2002 Long-lasting adverse effects of prenatal hypoxia on developing autonomic nervous system and cardiovascular parameters in rats. Pflugers Archiv 443 858-865.

Phillips DI \& Barker DJ 1997 Association between low birthweight and high resting pulse in adult life: is the sympathetic nervous system involved in programming the insulin resistance syndrome? Diabetic Medicine 14 673-677.

Roghair RD, Lamb FS, Miller FJ, Jr, Scholz TD \& Segar JL 2005 Early gestation dexamethasone programs enhanced postnatal ovine coronary artery vascular reactivity. American Journal of Physiology 288 R46-R53.

Russo D, Fraser R \& Kenyon CJ 1990 Increased sensitivity to noradrenaline in glucocorticoid-treated rats: the effects of indomethacin and desipramine. Journal of Hypertension 8 827-833.

Saruta T 1996 Mechanism of glucocorticoid-induced hypertension. Hypertension Research 19 1-8.

Seckl JR 2004 Prenatal glucocorticoids and long-term programming. European Journal of Endocrinology 151(Suppl 3) U49-U62.

Slotkin TA, Lappi SE, McCook EC, Tayyeb MI, Eylers JP \& Seidler FJ 1992 Glucocorticoids and the development of neuronal function: effects of prenatal dexamethasone exposure on central noradrenergic activity. Biology of the Neonate 61 326-336.

Stein HM, Martinez A, Blount L, Oyama K \& Padbury JF 1994 The effects of corticosteroids and thyrotropin-releasing hormone on newborn adaptation and sympathoadrenal mechanisms in preterm sheep. American Journal of Obstetrics and Gynecology 171 17-24.

Sugden MC, Langdown ML, Munns MJ \& Holness MJ 2001 Maternal glucocorticoid treatment modulates placental leptin and leptin receptor expression and materno-fetal leptin physiology during late pregnancy, and elicits hypertension associated with hyperleptinaemia in the early-growthretarded adult offspring. European Journal of Endocrinology 145 529-539.

Tonkiss J, Trzcinska M, Galler JR, Ruiz-Opazo N \& Herrera VL 1998 Prenatal malnutrition-induced changes in blood pressure: dissociation of stress and nonstress responses using radiotelemetry. Hypertension 32 108-114.

Torres A, Belser WW, III, Umeda PK \& Tucker D 1997 Indicators of delayed maturation of rat heart treated prenatally with dexamethasone. Pediatric Research 42 139-144.

Tseng YT, Tucker MA, Kashiwai KT, Waschek JA \& Padbury JF 1995 Regulation of beta 1 -adrenoceptors by glucocorticoids and thyroid hormones in fetal sheep. European Journal of Pharmacology 289 353-359.

Wallerath T, Witte K, Schafer SC, Schwarz PM, Prellwitz W, Wohlfart P, Kleinert H, Lehr HA, Lemmer B \& Forstermann U 1999 Down-regulation of the expression of endothelial NO synthase is likely to contribute to glucocorticoid-mediated hypertension. PNAS 96 13357-13362.

Weitz G, Deckert P, Heindl S, Struck J, Perras B \& Dodt C 2003 Evidence for lower sympathetic nerve activity in young adults with low birth weight. Journal of Hypertension 21 943-950.

Welberg LA, Seckl JR \& Holmes MC 2001 Prenatal glucocorticoid programming of brain corticosteroid receptors and corticotrophin-releasing hormone: possible implications for behaviour. Neuroscience 104 71-79.

Whitesall SE, Hoff JB, Vollmer AP \& D'Alecy LG 2004 Comparison of simultaneous measurement of mouse systolic arterial blood pressure by radiotelemetry and tail-cuff methods. American Journal of Physiology 286 H2408-H2415.

Whitworth JA, Brown MA, Kelly JJ \& Williamson PM 1995 Experimental studies on cortisol-induced hypertension in humans. Steroids 9 395-480.

Woodall SM, Johnston BM, Breier BH \& Gluckman PD 1996 Chronic maternal undernutrition in the rat leads to delayed postnatal growth and elevated blood pressure of offspring. Pediatric Research 40 438-443.

Woods LL 2006 Maternal glucocorticoids and prenatal programming of hypertension. American Journal of Physiology 291 R1069-R1075.

Woods LL \& Weeks DA 2005 Prenatal programming of adult blood pressure: role of maternal corticosteroids. American Journal of Physiology R955-R962.

Received in final form 4 October 2007

Accepted 1 November 2007

Made available online as an Accepted Preprint 1 November 2007 